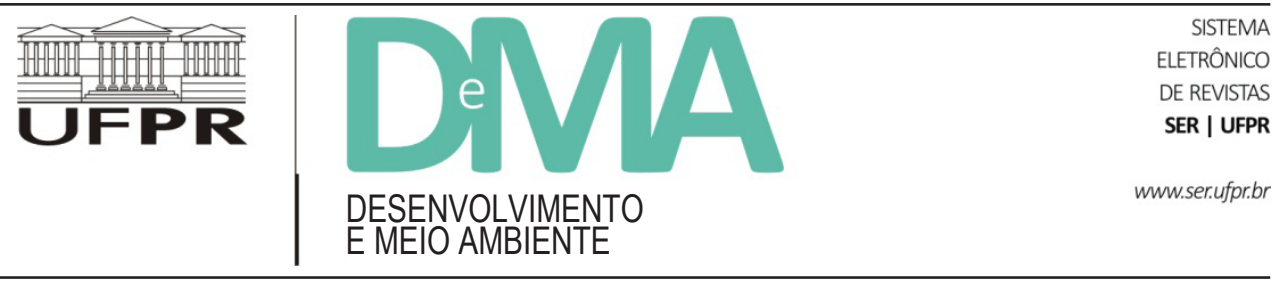

\title{
Conflitos ambientais, desenvolvimento no território e conflitos de valoração: considerações para uma ética ambiental com equidade social
}

\author{
Environmental Conflicts, Territorial Development and Conflicts of \\ Valuation: Considerations for Environmental Ethics and Social Equity
}

\author{
Luciano Félix FLORIT ${ }^{1 *}$ \\ ${ }^{1}$ Programa de Pós-Graduação em Desenvolvimento Regional (PPGDR), Universidade Regional de Blumenau (FURB), Blumenau, SC, Brasil. \\ *E-mail de contato: lucianoflorit@gmail.com
}

Artigo recebido em 2 de junho de 2015, versão final aceita em 9 de abril de 2016.

RESUMO: $\quad$ O artigo propõe uma inter-relação entre ética ambiental e a reflexão crítica sobre os processos de desenvolvimento, tendo como foco a análise sobre os conflitos entre sistemas de valores que subjazem aos conflitos ambientais que afetam comunidades tradicionais. O mesmo resulta de uma reflexão teórica que se apoia no trabalho realizado no âmbito do Grupo Interdisciplinar de Pesquisa em Desenvolvimento e Meio Ambiente (GIPADMA). Nesta análise, destacam-se as implicações dos usos da natureza praticados nos modos de vida tradicionais para a construção de uma ética ecológica que concilie equidade social e expansão da consideração moral para além dos humanos. Argumenta-se que a identificação destas implicações auxiliaria na formulação de estratégias argumentativas que reforcem o reconhecimento dos direitos territoriais destas populações. Ao mesmo tempo, entende-se que esta reflexão pode contribuir para a formulação de concepções de sustentabilidade socioambiental que defendam usos da natureza compatíveis com a sua consideração moral, isto é, usos da natureza não apoiados em perspectivas exclusivamente instrumentais. O artigo reúne elementos da ecologia política, a justiça ambiental e a ética ambiental, articulando-os ao campo da sociologia ambiental e da sociologia do desenvolvimento.

Palavras-chave: ética ambiental; justiça ambiental; conflitos ambientais; conflitos de valoração; desenvolvimento territorial sustentável.

ABSTRACT: The paper proposes an inter-relationship between environmental ethics and critical reflection on the development process, having as focus the analysis of conflicts between value systems that underlie the environmental conflicts affecting traditional communities. It results from a theoretical reflection based on the work carried out under the Interdisciplinary Research Group on Development and the Environment. In this analysis, we highlight the implications of the use of nature as practiced in traditional ways of life to build an ecological ethics that reconciles social equity and expansion of moral consideration beyond humans. It is argued that the identification of these implications would help on the formulation of argumentative strategies to enhance 
the recognition of the territorial rights of these people and, at the same time, contribute to the formulation of social and environmental sustainability conceptions that advocate uses of nature compatible with its moral consideration, that is, nature uses not held by exclusively instrumental perspectives. The article brings together elements of political ecology, environmental justice and environmental ethics linking them to the field of environmental sociology and the sociology of development.

Keywords: environmental ethics; environmental justice; environmental conflicts; valuation conflicts; sustainable territorial development.

\section{Introduçãa $o^{1}$}

As disputas por legitimar concepções de desenvolvimento, além de expressarem conflitos de interesse, expressam lutas em torno da visão sobre o dever ser dos processos de desenvolvimento. Trata-se de disputas simbólicas em torno de pressupostos normativos prescritivos que definem as finalidades substantivas do desenvolvimento.

Quando se qualifica o desenvolvimento com o adjetivo "sustentável" ou "ambiental" isto não é diferente, uma vez que a busca pela sustentabilidade ambiental, sempre justaposta a variáveis sociais, econômicas e tecnológicas, envolve sempre uma dimensão valorativa que preestabelece o rumo das decisões (Gudynas, 2004). Também não é diferente quando se acrescenta ao desenvolvimento sustentável a perspectiva "territorial", uma vez que a territorialidade se manifesta em operações de poder que definem o que pode ou não pode ser feito no território ou o que é aceitável ou inadmissível de um lado ou outro de uma fronteira (Sack, 2011). Disto resulta que os processos de desenvolvimento não sejam apenas decorrentes de fatores econômicos como produção, distribuição, trocas e consumo. Mas

[...] também um processo referido a condutas, hábitos e valores, individuais e coletivos - condicionado pelas relações de poder em que entram os indivíduos, os grupos e as classes sociais, que se encontram num dado espaço geográfico concreto (Theis, 2008, p. 13).

O reconhecimento desta dimensão valorativa, inerente às questões ambientais e à relação com a natureza, tem provocado problematizações específicas e a produção de subáreas acadêmicas, como a ética ambiental. Esta subárea tem produzido, nos últimos anos, resultados que recolocam na pauta de discussão as objeções ao antropocentrismo. Estas objeções foram agenda fundamental do ambientalismo, mas perderam espaço nos últimos anos diante de discussões mais pragmáticas voltadas à solução de problemas de interesse dos principais atores econômicos e políticos. Estes, apoiados nos paradigmas teóricos consagrados no emergente mainstream da política ambiental, têm se voltado, em geral, ao que foi conhecido como "ecologia de resultados" (Crespo, 2000, p. 217). Assim, enquanto poucas décadas atrás o ambientalismo parecia questionar os paradigmas dominantes do mundo, hoje, para muitos, tornou-se uma perspectiva genérica, fragmentada em pedaços temáticos, focada em consertar aspectos mais deletérios da atividade humana de modo pragmático (Leis, 2014). Com isto, uma parte significativa do ambientalismo parece ter renunciado à sua criticidade mais incisiva e à capacidade de articular suas problemáticas no debate público para além da divisão do trabalho disciplinar.

\footnotetext{
${ }^{1}$ O presente trabalho foi realizado com apoio do CNPq, Conselho Nacional de Desenvolvimento Científico e Tecnológico, Brasil, (nº do processo 157897/2015-0).
} 
Neste contexto, articular as contribuições da ética ambiental com a análise social implica em trazer importantes e renovados desafios à problemática ambiental. Em particular, questões voltadas a analisar as implicações ambientais dos processos de desenvolvimento e a conformação e consolidação de padrões de desenvolvimento no território.

Mas, a articulação destas duas discussões não é em absoluto algo simples ou trivial. De um lado, as proposições realizadas no campo da ética ambiental não oferecem respostas mais do que normativas para a tensão entre a consideração moral da natureza e os processos de desenvolvimento. Por outro, nas discussões sobre desenvolvimento, ao assumir o imperativo fundamental de contribuir para a equidade entre os seres humanos ${ }^{2}$ tende-se a deixar as considerações realizadas no campo da ética ambiental num plano secundário, ou mesmo a ignorá-las. Com efeito, mesmo quando atenta para as questões ambientais, o imperativo da equidade com relação aos processos de desenvolvimento tende, para os analistas das áreas das ciências sociais, a realçar o acesso equânime aos recursos e serviços ambientais e a condições de vida decentes para o conjunto da população. Em geral, isto é feito sem atentar para as objeções ao antropocentrismo levantadas por muitos analistas do campo filosófico da ética ambiental. $\mathrm{O}$ antropocentrismo, a que nos referimos, é o que admite consideração moral apenas a seres humanos e que, como consequência disto, tende a reconhecer aos outros seres vivos e à natureza um valor apenas instrumental. Este viés antropocêntrico, por vezes, tem sido inclusive encarado como uma bandeira e não como uma limitação, na medida em que assim estaria se superando um suposto "viés elitista" do ambientalismo clássico (Legarda \& Pardo Buendía, 2011) que, ao se focar em preservar a natureza, negligenciaria as relações sociais que criam desigualdades, ajudando a legitimá-las ${ }^{3}$.

Os processos de desenvolvimento expressam sistemas de relações sociais, muitas vezes conflitivas, que se consolidam em ordens econômicas e políticas mais ou menos duradouras, consagradas, protegidas e reproduzidas a partir do Estado ou com forte influência deste. O desenvolvimento se concretiza propriamente em padrões, no sentido de regularidades que resultam de práticas que, por se tornarem rotineiras, resultam em condicionantes para novas práticas ${ }^{4}$. Assim, as diversas trajetórias dos processos de desenvolvimento constituem experiências históricas peculiares, de escalas mais ou menos amplas, que, em geral, derivam de diferentes combinações e dosagens da importância reconhecida pelo Estado às diversas concepções dos agentes do mercado e da sociedade civil envolvidos no processo $^{5}$. Essas diferentes trajetórias se definem num campo de lutas no qual os agentes em disputa organizam suas forças no intuito de constituir um poder simbólico que legitime suas próprias concepções normativo-prescritivas.

\footnotetext{
${ }^{2}$ Refere-se aqui à ambígua noção de desenvolvimento que busca distinguir o mesmo do mero crescimento econômico, apontando a necessidade de envolver diversos grupos, classes, instituições, etc., num processo complexo e politicamente orientado que, supostamente, poderia garantir equidade na distribuição dos benefícios desse crescimento.

${ }^{3}$ A categoria de antropocentrismo merece, por si mesma, uma análise específica em função dos diversos sentidos com que é utilizada em diferentes contextos. Serve, no entanto, a definição apresentada no corpo do texto para a discussão exposta neste artigo. Outras considerações relativas a esta categoria podem ser encontradas, por exemplo, em Norton, B. (2009) e Hargrove, E. (2009).

${ }^{4}$ Esta concepção de padrão de desenvolvimento como resultante de práticas rotineiras, que resultam em condições objetivas, remete a uma concepção teórica estrutural construtivista, apoiada nas concepções de agência e condicionantes estruturais de Giddens (1989) e Bourdieu (1993).

${ }^{5}$ Incluo na sociedade civil os diversos grupos sociais, nas suas diferentes formas de organização, que disputam com os agentes do mercado as concepções que serão consagradas pelo Estado.
} 
Não é rara, neste contexto, a confrontação entre sistemas de valores aparentemente irreconciliáveis entre agentes comprometidos com perspectivas de equidade social e agentes que tendem a reconhecer algum tipo de valor intrínseco à natureza. Os primeiros, inclinados a aceitar tacitamente um olhar antropocêntrico e instrumental da natureza, e os segundos insistindo, em última análise, em que a realização das necessidades humanas não deveria se consumar às custas da degradação de paisagens naturais ou do desrespeito à vida de seres não humanos. No entanto, esta clivagem não resolve os desafios ético-políticos deflagrados pelos processos de desenvolvimento contemporâneos. Isto porque os processos sociais que resultaram nas desigualdades que o apelo à equidade tenta remediar, muitas vezes estão, eles próprios, assentados numa específica valoração do ambiente e da natureza que requer, ela mesma, uma reflexão crítica. Como reconhece Eduardo Gudynas,

Na construção do desenvolvimento sustentável as considerações sobre os valores são cruciais. As visões tradicionais ${ }^{6}[\ldots]$ em boa medida respondem a uma longa história que tem valorado o ambiente em função da utilidade para o ser humano. Concebem a Natureza como objeto de valores. Por outro lado, as perspectivas mais inovadoras [...] apostam num ambiente sujeito de valores. Por sua vez, na construção de estratégias de sustentabilidade novamente aparece uma carga ética quando se demandam comportamentos respeitosos do ambiente, ou se interpõe a sobrevida de uma espécie diante de um projeto produtivo. Uma e outra vez aparecem os problemas éticos, seja na própria prática dos profissionais envolvidos em temas ambientais, nos comportamentos de quem desenha as políticas de desenvolvimento em nossos países, assim como nas concepções de toda a sociedade em relação à Natureza. [...] Seja evidente ou não, sempre existe um componente ético nas abordagens sobre sustentabilidade. Em alguns casos, este é reduzido ou escondido [...] enquanto que em outras perspectivas o que se busca é ampliá-lo e fortalecê-lo (Gudynas, 2004, p. 189, do espanhol - tradução nossa).

Compreende-se, então, a necessidade de que a análise social e ético-política dos conflitos ambientais dialogue e se aproxime das análises sistemáticas sobre os fundamentos normativos das relações com a natureza e os seres vivos não humanos e os conflitos de valoração deles decorrentes. E, a partir disto, os correlacione com a dinâmica social, política, econômica e territorial que constitui a condição de possibilidade destes conflitos.

Do ponto de vista metodológico, o artigo é resultado de análise teórica baseada em pesquisa bibliográfica e discussões realizadas no contexto do Grupo Interdisciplinar de Pesquisa em Desenvolvimento e Meio Ambiente (GIPADMA), que desenvolveu pesquisas teóricas e empíricas sobre os diversos aspectos aqui tratados.

Além desta Introdução (Parte 1) e das Considerações Finais (Parte 5), o artigo se subdivide em três seções. Na primeira delas (Parte 2), explicamos o que é ética ambiental, enfatizando como a mesma se conecta com a discussão em torno do desenvolvimento. Para tanto, utilizamos uma classificação das diferentes correntes por meio da distinção entre individualistas e holistas, a partir da qual elaboramos uma tabela que evidencia como as mesmas guardam relação com atores sociais que tendem a assumi-las como discurso. Na segunda (Parte 3), apresentamos a perspectiva da Justiça Ambiental, evidenciando que a equidade social é

\footnotetext{
${ }^{6}$ Gudynas utiliza aqui a expressão "visões tradicionais" para se referir às concepções de natureza historicamente produzidas pelo processo de colonização e o projeto civilizatório da modernidade, e não no sentido das perspectivas das "populações tradicionais", que tendem a possuir concepções de natureza diferenciadas das convencionais entre os sujeitos e instituições tipicamente modernas.
} 
seu fundamento ético-político, sendo que as iniquidades apontadas observam especialmente uma dimensão territorial. Nosso argumento é de que esta dimensão territorial resulta no envolvimento de populações tradicionais que sustentam, nos seus modos de vida, valorações da natureza diferenciadas da predominante nas sociedades de capitalismo globalizado. Por fim, na terceira seção (Parte 4), discutimos a importância de retomarmos a discussão crítica do antropocentrismo, conciliando a busca da equidade proposta pela Justiça Ambiental com a discussão, apresentada pela Ética Ambiental, sobre a consideração moral de seres vivos não humanos. Neste sentido, analisamos alguns obstáculos epistemológicos a esta conciliação. Esta análise resultou no argumento de que as valorações da natureza dos povos tradicionais contêm uma potencialidade heurística importante para o amadurecimento de uma ética ecológica de dupla inclusividade, ou seja, uma ética ecológica capaz de conciliar equidade social com consideração moral de seres vivos não humanos.

\section{2. Ética ambiental e desenvolvimento}

A ética ambiental é o campo de reflexão (muitas vezes crítica) sobre os fundamentos dos valores a partir dos quais se estabelecem as relações com a natureza e os seres vivos não humanos. É a especialidade da ética que atende a questões como: se justifica uma atividade que criará empregos, mas provocará a extinção de espécies? É melhor proteger um parque natural do que produzir energia que melhorará a vida de determinadas pessoas? Devemos nos importar se um empreendimento humano provoca a morte de animais?

Respostas a estas questões não podem ser estabelecidas com base somente em informações fáticas, como a quantidade de energia que produzirá uma barragem ou a utilidade médica potencial de uma espécie vegetal. Ainda que tais informações possam ser úteis para uma decisão, os problemas envolvidos requererão julgamentos de valor, os quais se apoiarão em preferências, aspirações, critérios de eficiência ou princípios morais propriamente ditos.

Tais julgamentos de valor, por vezes, podem simplesmente reproduzir uma moralidade naturalizada ou dominante, encobrindo inconsistências e até falácias suscetíveis de reflexão crítica.

Uma distinção semântica é oportuna aqui. Entende-se ética como sinônimo de filosofia da moral, isto é, como a reflexão sistemática sobre os valores morais realizada com o intuito de se chegar a uma conclusão sobre se uma ação deve ser considerada correta ou incorreta. Entende-se por moralidades os valores dominantes em grupos ou sociedades que tendem a ser repassados de geração a geração de forma indissociável à reprodução de valores culturais e de práticas sociais rotineiras. Assim, embora muitas vezes o raciocínio ético não nos leve a colidir com a moralidade dominante, em certas ocasiões ocorre justamente o contrário, ou seja, o raciocínio ético leva ao questionamento de uma dada moralidade socialmente estabelecida. Este último é o que acontece com muitos dos raciocínios elaborados no contexto da ética ambiental em relação ao antropocentrismo, naturalizado na moralidade dominante, que concede reconhecimento moral apenas aos seres humanos, legitimando, como se verá, práticas especistas. As moralidades estão intimamente relacionadas aos processos de reprodução social e, no que diz respeito à natureza no contexto da sociedade capitalista, tendem a reconhecer nela um valor apenas instrumental. A reflexão da ética ambiental analisa criticamente este entendimento, em muitos casos concluindo que haveria na natureza algum tipo de valor intrínseco. 
Ou seja, que deveríamos reconhecer na natureza valores em si mesma, independente da utilidade instrumental que esta eventualmente tiver para os humanos. Esta afirmação não esgota as controvérsias, na medida em que a valoração sempre seria feita por um sujeito, o que para alguns implicaria em admitir que não haveria, portanto, valor intrínseco propriamente dito. Contudo, para além desta controvérsia, parece existir concordância entre a maioria dos autores em admitir que considerar a natureza e os seres vivos não humanos, que dela fazem parte, apenas pelo seu eventual valor instrumental, não tem sustentação. É esta redução da natureza e dos seres vivos não humanos à sua consideração meramente instrumental e a consequente redução à categoria de mera coisa que constitui o âmago da objeção que a ética ambiental estabelece diante da ética tradicional ocidental.

Assim, no intuito de avaliarmos se as ações em relação à natureza são eticamente justificáveis, a ética ambiental formula questões como: um ser vivo tem valor em si mesmo ou apenas vale alguma coisa se for útil para satisfazer necessidades de pessoas? Temos obrigações morais em relação à Natureza como um todo, ou as teríamos em relação a espécies, a seres vivos individualmente ou então às unidades de paisagem naturais? Um indivíduo de uma espécie silvestre é mais importante do que um de uma espécie domesticada?

É importante constatar aqui que se, por um lado, o segundo leque de questões remete à análise abstrata e específica de um ramo da filosofia, o primeiro remete a circunstâncias que, não raro, se colocam no desenrolar dos processos de desenvolvimento concretos e, por vezes, estão no cerne de conflitos ambientais. Quando se trata de decisões com implicações políticas num contexto democrático - que, por definição, implica na convivência de diversos sistemas de valores -, resulta imprescindí- vel a reflexão crítica sobre os pressupostos morais que dão suporte às decisões que afetam a natureza e os seres vivos não humanos. Esta reflexão crítica é um momento fundamental que, se omitido, enfraquece a legitimidade das decisões.

Existem diversas correntes na ética ambiental e também diversas formas de classificá-las. Robert Elliot (2004), num artigo que constitui uma boa apresentação e introdução à área, classifica as éticas ambientais em quatro abordagens: a) centrada no ser humano; b) centrada nos animais; c) centrada na vida; e d) ética do todo ou holismo ecológico. Esta classificação foi realizada com base num problema fundamental da ética ambiental, que é o do grau de expansão do círculo de consideração moral. Em que medida e por quais razões teríamos responsabilidade moral com seres não humanos? Esta responsabilidade inclui os animais e outros seres vivos, como plantas ou unidades de paisagens? Há diversas respostas possíveis a estas indagações, que se valem de modo diferenciado das fontes filosóficas clássicas da tradição ocidental na tentativa de encontrar suportes filosoficamente consistentes, muitas vezes por meio de uma reflexão crítica sobre elas.

Embora seja possível encontrar justificativas para lidar com a natureza considerando exclusivamente as necessidades dos seres humanos - como é feito mais habitualmente quando se discute o desenvolvimento sustentável -, existe a convicção, compartilhada entre muitos pensadores da ética ambiental, de que um dos traços mais problemáticos do modo como a civilização ocidental vem lidando com a natureza está no seu exacerbado antropocentrismo. Este, que é definido e amparado nas suas tradições religiosas (judaico-cristãs) e filosófico-morais, notadamente as escolas aristotélica, kantiana, utilitarista e contratualista (Rachels, 2013), se reflete nas concepções políticas, econômicas e 
desenvolvimentistas que historicamente levaram à prática a moralidade que justificou o impulso em transformar a natureza para o domínio humano ${ }^{7}$.

A potencialidade reflexiva desta área para as discussões sobre os imperativos éticos e políticos do desenvolvimento fica evidente se estabelecermos uma distinção entre as correntes holistas e individualistas da ética ambiental.

Os primeiros afirmam que, uma vez que a preocupação primária do ambientalismo são entidades que constituem totalidades, como ecossistemas e espécies, a ética ambiental deve se ocupar em fundamentar o estatuto moral ou valor intrínseco destas entidades. Para tanto, deve se apegar a alguma forma de holismo para o qual os paradigmas clássicos estão mal preparados. Estas entidades totais que formam o cerne da preocupação holista são compostas tanto por elementos bióticos (animais, plantas, etc.) quanto por componentes abióticos (rios, pedras, etc.). Esta forma de justificação explora a necessidade de sistematizar as implicações éticas do legado darwinista, o qual, por sua vez, informa a visão de mundo do pensamento preservacionista e das ciências biológicas de modo geral (Callicott, 2001).

Já os pensadores de linha individualista buscam fundamentos éticos para defender o valor moral de indivíduos vivos não humanos, entendendo que esta fundamentação poderia dar bases mais consistentes e evitaria novos problemas que se suscitam ao defender entidades totais ${ }^{8}$. Neste sentido, Paul Taylor (2011), apoiado em fundamentos kantianos, defende uma perspectiva biocêntrica, na qual teríamos responsabilidades morais com "cada organismo individual [...] que é uma unidade de vida teleológica - ou seja, que persegue objetivos - que busca seu próprio bem de uma maneira que lhe é única" (Taylor, 2011, p. 44-45). Já numa outra perspectiva, também focada em indivíduos não humanos, os seres com os quais temos responsabilidade moral são aqueles que têm capacidade de ter sensações, de sentir dor e de sofrer, aos quais se qualifica como "seres sencientes". Nesta linha, e por meio de uma argumentação consequencialista formulada na tradição utilitarista, Peter Singer (2002, 2004) defende que a qualidade da senciência é razão suficiente para compreender que esses seres teriam interesses, os quais deveriam ser levados em consideração, independente da espécie à qual pertençam. A negação dos interesses de seres sencientes pelo fato de não serem humanos - ou seja, em função da sua espécie - seria incorrer em especismo, afirma o autor. Já por meio de uma argumentação kantiana, Tom Regan (2006) defende que esses seres devem ser considerados "sujeitos de uma vida", o que os torna dignos de direitos. Conforme o autor, ao serem portadores de direitos estes seres não poderiam, em hipótese alguma, terem violada a sua dignidade e interesse, independente do cálculo de benefício geral que eventualmente possa se fazer diante de uma hipótese de uso instrumental dos mesmos.

Os argumentos que se apoiam na senciência, como os de Singer, incluem evidentemente todos os animais de sistema nervoso mais complexo, deixando dúvidas em relação a outras categorias de animais. Estes, cuja inclusão na consideração moral é questionável ou duvidosa por meio da senciência, poderiam, por sua vez, vir a ter seus interesses

\footnotetext{
${ }^{7}$ Keith Thomas e Raúl Claro são alguns dos autores cujas análises críticas expõem como se justificou moralmente na modernidade o impulso em transformar a natureza para o domínio humano (Thomas, 1988) e como isto foi incorporado pela trajetória da noção de desenvolvimento, incorporação hoje fortemente questionada (Claro, 2011).

${ }^{8}$ Para aprofundar o debate entre individualistas e holistas ver, por exemplo, Varner (2001) e a resposta de Callicot (2001).
} 
preservados com base na categoria de "sujeitos de uma vida" de Regan (2006), tornando-se esta última uma categoria mais inclusiva.

Cabe esclarecer que, embora as linhas de raciocínio de Singer $(2002,2004)$ e Regan (2006) sejam, muitas vezes, chamadas de "animalistas", também têm implicações para a defesa de unidades de paisagem mais amplas, que incluem vegetais, elementos abióticos, etc. Isto se verifica na medida em que, em condições naturais, os indivíduos sencientes silvestres não teriam condições de garantir seus interesses senão com a preservação dos ecossistemas ou unidades de paisagem dos quais fazem parte. Por outro lado, as perspectivas individualistas proporcionam alicerces para a reflexão sobre a ética do tratamento que humanos emprestam tanto aos animais silvestres quanto aos domésticos. O mesmo não ocorre com as perspectivas holistas, que têm como foco de preocupação unidades de paisagem "naturais" ou silvestres, excluindo da sua preocupação as espécies domésticas criadas por humanos.

Esta classificação não é exaustiva, na medida em que deixa fora vários autores importantes. Ela foi concebida com o intuito de dar realce às nuances argumentativas consideradas mais marcantes para a discussão aqui proposta, voltada a examinar a lacuna da consideração moral a seres vivos não humanos.

A Tabela 1 apresenta estas correntes, classificadas pelas escalas de consideração moral holista e individualista. Nessa tabela, se incluem também tipos de ativistas sociais para os quais essas perspectivas constituem um fundamento importante no seu discurso político. A apropriação das perspectivas filosóficas por parte dos grupos de ativistas nem sempre é explícita, consciente e fiel das respectivas escolas. Ela frequentemente é implícita e, por vezes, até parcial, no sentido de que a razão da apropriação dos ativistas é justamente a ação na qual os discursos se constituem em práticas que se definem em contextos específicos.

Mas, resgatar a crítica ao antropocentrismo no campo da análise socioambiental e das ciências sociais não pode representar, evidentemente, o abandono da preocupação ético-política que busca modelos de desenvolvimento socialmente inclusivos, bem como a interpelação ao modo desigual e desproporcional com que muitas vezes são distribuídos os ônus ambientais e o acesso aos recursos e serviços ambientais nos padrões de desenvolvimento dominantes. Em outras palavras, a crítica ao antropocentrismo não pode ser realizada

TABELA 1 - Holismo e individualismo nas correntes da Ética Ambiental.

\begin{tabular}{|c|c|c|c|c|}
\hline $\begin{array}{c}\text { Escala de } \\
\text { consideração } \\
\text { moral }\end{array}$ & $\begin{array}{c}\text { Corrente da Ética } \\
\text { Ambiental }\end{array}$ & $\begin{array}{c}\text { Escola filosófica da qual é } \\
\text { tributária }\end{array}$ & $\begin{array}{c}\text { Autores } \\
\text { contemporâneos da } \\
\text { Ética Ambiental }\end{array}$ & $\begin{array}{c}\text { Ativistas sociais que } \\
\text { assumem como discurso }\end{array}$ \\
\hline Holismo & $\begin{array}{l}\text { Holismo } \\
\text { preservacionista }\end{array}$ & $\begin{array}{l}\text { Darwinismo } \\
\text { Ética da Terra de Aldo Leopold }\end{array}$ & J. Baird Callicot & $\begin{array}{l}\text { Ambientalistas } \\
\text { preservacionistas }\end{array}$ \\
\hline \multirow{3}{*}{ Individualismo } & $\begin{array}{l}\text { Biocentrismo } \\
\text { individualista } \\
\end{array}$ & Filosofia kantiana & Paul W. Taylor & Ecologistas biocêntricos \\
\hline & \multirow{2}{*}{ Sencientismo } & Consequencialismo utilitarista & Peter Singer & Animalistas bem-estaristas \\
\hline & & Filosofia kantiana & Tom Regan & Animalistas abolicionistas \\
\hline
\end{tabular}

FONTE: Florit \& Grava (2014). 
à custa de abandonar as premissas normativas da equidade social com relação à dimensão ambiental dos processos de desenvolvimento.

\section{Justiça ambiental, território e equidade}

Boa parte dos autores que vêm se dedicando a discutir o aspecto da equidade em relação à dimensão ambiental do desenvolvimento têm se autorrotulado como partícipes da corrente da Justiça Ambiental. No Brasil, o uso do conceito de justiça ambiental incorpora movimentos com antecedentes significativos, como os movimentos de pessoas atingidas por barragens (MAB) e mais recentemente, dentre outros, os movimentos deflagrados por populações tradicionais (índios, ribeirinhos, etc.), populações estas cujo modo de vida é ameaçado pelas obras de infraestrutura realizadas no impulso neodesenvolvimentista da última década. Trata-se de expressões de "conflitos ambientais" resultantes de "conflitos ecológicos distributivos" (Martinez-Alier, 2007), os quais são decorrentes da apropriação material, territorial, econômica e simbólica dos diversos recursos e serviços naturais, de maneira desigual.

Estes conflitos têm provocado a emergência de práticas de resistência por diversos grupos e movimentos sociais - as denominadas organizações que lutam por justiça ambiental -, habitualmente compostas por ambientalistas, populações atingidas, entidades e movimentos sociais solidários, por vezes apoiados por grupos acadêmicos engajados.

Porto (2013) apresenta uma tipologia segundo a qual existem quatro âmbitos principais nos quais ocorrem os conflitos ambientais no Brasil (Tabela 2). No interior destes âmbitos, entram em confrontação setores econômicos extremamente dinâmicos - com suas correspondentes derivações nas cadeias industriais -, com grupos sociais vulneráveis que têm ameaçados os seus direitos territoriais e a continuidade de seus modos de vida. $\mathrm{O}$ primeiro destes está relacionado à produção de biomassa por meio do agronegócio de exportação de commodities rurais. Aqui se enquadram os setores dedicados aos monocultivos, à carcinicultura e à pecuária. $\mathrm{O}$ segundo se refere à mineração de metais e de petróleo - incluindo o seu processamento para a produção de commodities, como derivados de petróleo, aço e alumínio. O terceiro está constituído pela produção de energia e grandes obras de infraestrutura associadas (barragens, usinas hidrelétricas, termoelétricas e usinas nucleares) e outras obras de infraestrutura, como as barragens de contenção, hidrovias, rodovias, gasodutos e minerodutos, e transposição e integração de bacias hidrográficas. O quarto é composto pelos conflitos urbanos, onde a segregação espacial obriga vastas populações a viver e a trabalhar em condições pe-

TABELA 2 - Âmbitos de conflitos ambientais no Brasil.

\begin{tabular}{|c|c|c|c|}
\hline $\begin{array}{c}\text { Biomassa } \\
\text { Agronegócio }\end{array}$ & Mineração & $\begin{array}{c}\text { Energia } \\
\text { Infraestrutura }\end{array}$ & Espaço Urbano \\
\hline $\begin{array}{l}\text { Monocultura } \\
\text { Carnicicultura } \\
\text { Pecuária }\end{array}$ & $\begin{array}{l}\text { Metais } \\
\text { Petróleo } \\
\text { Carvão }\end{array}$ & $\begin{array}{l}\text { Barragens } \\
\text { Hidroelétricas } \\
\text { Hidrovias } \\
\text { Rodovias } \\
\text { Minerodutos }\end{array}$ & $\begin{array}{l}\text { Segregação Urbana } \\
\text { Exposição desproporcional a } \\
\text { desastres "naturais" }\end{array}$ \\
\hline
\end{tabular}

FONTE: Florit \& Grava (2014), elaborado com base em Porto (2013). 
rigosas ou indignas, devido à falta de saneamento básico e outros equipamentos urbanos e à exposição desproporcional a riscos de poluição e a desastres ditos "naturais" (Porto, 2013).

Atentar aos âmbitos em que acontecem os principais conflitos ambientais permite perceber com clareza que os mesmos, em geral, envolvem espaços geográficos com populações cujo modo de vida está intimamente relacionado com as próprias valorações da natureza. Com efeito, salvo no caso dos conflitos ambientais tipicamente urbanos, todos os âmbitos mencionados afetam populações que detêm concepções da natureza peculiares, como indígenas, quilombolas, agricultores parcialmente integrados ao mercado ou voltados à agroecologia e diversas categorias de comunidades tradicionais, como extrativistas, ribeirinhos, pescadores artesanais, faxinalenses, etc.

As concepções de natureza destes grupos, embora contenham uma valoração de uso da natureza na medida em que dependem do uso direto desta para atender suas necessidades de subsistência, não implicam numa redução da natureza a um estatuto meramente instrumental. Pelo contrário, trata-se de uma relação com a natureza carregada de sentidos e significações simbólicas e de práticas de uso que denotam uma simultaneidade entre o uso dela e a sua consideração moral.

Por outro lado, estas valorações, além de diversas e culturalmente situadas, são, na maioria das vezes, incomensuráveis, especialmente se comparadas com a valoração monetária realizada no âmbito do mercado e com a qual operam os atores mais fortes no contexto do padrão de desenvolvimento dominante (Martinez-Alier, 2007). Assim, eles refletem uma multiplicidade inerente às diversas concepções culturais e lógicas de uso, própria da diversidade de sujeitos (Acselrad, 2010).
Esta incomensurabilidade de valores se reflete na diversidade de modos de vida nos quais a natureza e a paisagem constituem valores de uso, não redutíveis à mera monetarização em função de que detêm uma condição dual de significação simbólica e provimento material. Tal diversidade se manifesta também na dimensão territorial dos modos de vida que se formam indissociavelmente ao locus específico da sua vivência, que constituem os seus lugares. Estes são definidos pelos povos e populações na constituição de modos de vida peculiares que observam uma fraca ou parcial integração ao mercado e que, por serem ameaçados, muitas vezes, se contrapõem aos projetos e obras que se proclamam como "portadoras do desenvolvimento".

Estes processos de resistência detêm uma importância ímpar para um planejamento sustentado numa perspectiva ético-política capaz de equacionar equidade e justiça ambiental com o reconhecimento da diversidade de valorações com que a natureza é de fato definida. Como afirmam Zhouri e Oliveira (2010, p. 444),

\begin{abstract}
Um dos desafios para a pluralidade cultural e para a democracia seria a contemplação dessas várias realizações e experiências dos lugares. Isso remete ao poder das pessoas optarem por permanecer no lugar, ressignificando-o e transformando-o continuamente, como atestam várias lutas sociais hoje, como a luta contra o avanço das barragens, das monoculturas do agrodiesel, enfim, as formas industriais de ocupação do espaço para o capital, mercadoria a ser incorporada nos fluxos globais em detrimento dos sentidos diversos dos lugares.
\end{abstract}

Reconhecer esta diversidade implica em reconhecer também que os sujeitos, além de serem "portadores de visões concorrenciais sobre o meio ambiente e a natureza", também se localizam desigualmente na sociedade, o que tende a implicar na distribuição também desigual dos recursos e 
dos riscos do desenvolvimento (Zhouri \& Oliveira, 2010, p. 444). Estas visões concorrenciais sobre o meio ambiente e a natureza incluem, em alguns casos, concepções não exclusivamente instrumentais, diferentes das que estão embutidas nos processos de desenvolvimento em curso nos três âmbitos de conflitos ambientais não urbanos?.

\section{Populações tradicionais, conflitos de valoração e dupla inclusividade}

Utilizamos aqui o termo "povos tradicionais" num sentido amplo, entendendo as comunidades que participam de modos de vida - modos de atender suas necessidades materiais de subsistência e de constituição simbólica -, com fraca inserção no mercado capitalista (Danowski \& Viveiros de Castro, 2014). Esta relação de não integração completa no mercado e suas instituições tende a ser arena de conflitos de apropriação e de valoração entre os agentes dos "projetos de desenvolvimento" e as comunidades que têm seus modos de vida e lógicas de uso da natureza ameaçadas. Para Martínez-Alier (2007, p. 353), "existe um choque de sistemas de valoração quando os discursos da justiça ambiental, dos direitos territoriais indígenas ou da segurança ambiental se desdobram em oposição à valoração monetária dos riscos e das cargas ambientais".

Estes conflitos de valoração não implicam apenas conflitos econômicos, como afirmam Funtowicz e Ravetz (1994),

Em primeiro lugar, o valor monetário será observado como a medida de um só aspecto de valor que reflete um tipo particular de interesse, aquele que encontra expressão principalmente por intermédio do mercado comercial. Escolher uma definição operacional particular de valor implica tomar uma decisão a respeito do que é real e importante; outras definições refletirão as crenças e interesses de outros atores... Isso implica uma pluralidade de perspectivas e valores (Funtowicz \& Ravetz (1994), apud Martinez-Alier (2007, p. 354), grifo nosso).

Significa dizer que a atribuição de valor monetário, procedimento operacional de valoração no qual todos os valores são reduzidos a uma única escala, só é possível na medida em que algumas qualidades dos entes valorados são consideradas importantes e outras são desconsideradas.

O reconhecimento das múltiplas valorações, concepções socioculturais e lógicas de uso da natureza, encarnadas por sujeitos que sustentam modos de vida tradicionais, é uma condição sine qua non de justiça ambiental em conflitos que envolvem estas populações.

Mas, este reconhecimento também contém um potencial heurístico importante para a perspectiva da justiça ambiental: discutir a inclusão da consideração moral de outras formas de vida que não a humana. Em outras palavras, o reconhecimento dos valores das culturas não dominantes pode contribuir para uma perspectiva capaz de questionar em termos éticos o antropocentrismo dominante, uma vez que as populações envolvidas, muitas vezes, representam exemplos de lógicas de uso que convivem com formas específicas de consideração moral. Estas lógicas de uso, embora divergentes das visões biocêntricas ou senciocêntricas no modo em que são formuladas pelos filósofos apresentados acima, certamente também não são compatíveis

\footnotetext{
${ }^{9}$ Isto não significa dizer que os conflitos ambientais urbanos não resultem, também, da contraposição de lógicas de uso do território, apoiadas inclusive em valorações e conteúdos simbólicos peculiares e altamente significativos. Contudo, neste artigo, ocupamo-nos dos conflitos que envolvem populações cujos modos de vida se realizam, materialmente falando, por meio do uso direto da natureza. Estes modos de vida se encontram, via de regra, em espaços não urbanos.
} 
com o antropocentrismo exacerbado que predomina atualmente no capitalismo globalizado. Assim, estes conflitos de valoração detêm uma potencialidade heurística enorme no contexto atual da discussão ambiental, cuja relevância extrapola o interesse das populações afetadas, já por si imenso. Estes conflitos podem incentivar certos setores urbanos já sensíveis, tornando-os mais enérgicos em apoiar uma reflexão crítica sobre os processos de desenvolvimento que negligenciam tanto a consideração moral dos seres vivos não humanos quanto os modos de vida fracamente inseridos no mercado.

Essa potencialidade heurística é percebida por Eduardo Viveiros de Castro (2014) que, ao se referir ao modo como culturas indígenas lidam com os animais e outros seres vivos não humanos, comparativamente ao modo como se lida com eles no contexto da sociedade moderna de capitalismo globalizado, expressou isto da seguinte forma:

[...] os animais seriam pessoas, isto é, são seres que têm valor intrínseco. É isso o que significa ser pessoa. Reconhecer direitos aos demais viventes não é reconhecer direitos humanos aos demais viventes. É reconhecer direitos característicos e próprios daquelas diferentes formas de vida. Os direitos de uma árvore não são os mesmos direitos de um cidadão brasileiro da espécie homo sapiens. O que não quer dizer, entretanto, que ela não tenha direitos. Por exemplo, o direito à existência, que só pode ser negado sob condições que exigem reflexão. Os índios não acham que as árvores são iguais a eles. O que eles acham simplesmente é que você não faz nada impunemente. Todo ser vivo, com exceção dos vegetais, tem que tirar a vida de um outro ser vivo para sobreviver. A diferença está no fato de que os índios sabem disso. E sabem que isso é algo sério. Nós estamos acostumados a fazer a nossa caça nos supermercados, não somos mais capazes de olhar de frente uma galinha antes de matá-la para comer. Assim, perdemos a consciência de que nós vivemos num mundo em que viver é perigoso e traz consequências. E que comer tem consequências. Os animais seriam pessoas no sentido de que eles possuem valor intrínseco, eles têm direito à vida, e só podemos tirar a vida deles quando a nossa vida depende disso. Isso é uma coisa que, para os índios, é absolutamente claro. Se você matar à toa, você vai ter problemas. Eles não estão dizendo que é tudo igual. Eles estão dizendo que tudo possui um valor intrínseco e que mexer com isso envolve você mesmo (Viveiros de Castro, 2014, p. 1).

Significa dizer que existe uma conexão analítica importante a ser desenvolvida ao olhar os conflitos de valoração decorrentes dos conflitos ambientais que envolvem populações tradicionais, trazendo para esta análise categorias da ética ambiental. Esta conexão poderá auxiliar na formulação de uma ética ecológica que concilie a consideração moral de seres vivos não humanos com a equidade social inerente à luta pelos direitos territoriais e permanência nos lugares por parte de comunidades tradicionais.

A Tabela 3 cria uma tipologia de perspectivas com relação às duas dimensões de inclusividade (equidade social + expansão da consideração moral para além dos humanos). Nela se evidenciam o tipo de inclusividade que uma ou outra consegue atender e o tipo de inclusividade que fica sem tratamento. Fica evidenciada, assim, o que denominamos aqui Ética e Justiça Ecológica, uma expressão ainda sem tratamento consolidado, que efetive o cruzamento de ambos os tipos de inclusividade ${ }^{10}$. A mesma ta-

\footnotetext{
${ }^{10}$ Deve-se atentar para o fato de que as expressões aqui citadas podem, em alguns casos, ser utilizadas com sentidos diferentes por alguns autores. No contexto deste artigo, tem se utilizado até aqui a expressão "Ética Ambiental” para se referir à discussão da consideração moral dos seres vivos não humanos e a expressão "Justiça Ambiental" para se referir à discussão que se preocupa pela iniquidade com que se distribuem os ônus ambientais no capitalismo globalizado. Utiliza-se agora a expressão "Ética e Justiça Ecológica" para se referir à perspectiva ético-política que busca consumar a dupla inclusividade, isto é, equidade socioambiental acrescida da expansão da consideração moral para além dos humanos. Por outro lado, as referências aos modos de vida de povos e populações tradicionais não são no sentido de pregar sua assimilação, mas de mostrar conteúdos de fato já existentes em modos de vida concretos, nos quais a iniquidade entre seres humanos e a coisificação da natureza não é a
} 
bela evidencia também aquela que não se preocupa por nenhuma das duas inclusividades. Esta seria a perspectiva ambiental, que se foca apenas nas inovações tecnológicas para a eficiência ecológica e na incorporação de mecanismos de mercado verde, sem considerações relevantes com relação às iniquidades sociais nem para a coisificação dos seres vivos não humanos.

TABELA 3 - Tipologia de perspectivas ambientais com relação a sua inclusividade (equidade social + expansão da consideração moral para além dos humanos).

\begin{tabular}{lll}
\hline & $\begin{array}{l}\text { Sem equidade } \\
\text { (- Inclusivo) }\end{array}$ & $\begin{array}{l}\text { Com equidade } \\
\text { (+ Inclusivo) }\end{array}$ \\
\hline $\begin{array}{l}\text { Sem expansão da } \\
\text { consideração moral } \\
\text { (- Inclusivo) }\end{array}$ & $\begin{array}{l}\text { Eficiência } \\
\text { Ecológica }\end{array}$ & $\begin{array}{l}\text { Justiça } \\
\text { Ambiental }\end{array}$ \\
$\begin{array}{l}\text { Com expansão da } \\
\text { consideração moral } \\
(+ \text { Inclusivo) }\end{array}$ & Ética Ambiental & $\begin{array}{l}\text { Ética e Justiça } \\
\text { Ecológica }\end{array}$ \\
\hline
\end{tabular}

FONTE: Adaptado de Florit \& Grava (2014).

As razões que explicam a precária consolidação de perspectivas que poderiam se enquadrar na Ética e Justiça Ecológica são diversas e não temos a pretensão de elucidá-las por completo neste artigo. Contudo, existem algumas constatações que consideramos relevante mencionar.

Existe uma continuidade, difícil de superar, da divisão do trabalho em lógicas disciplinares entre ciências humanas e ciências da natureza que se perpetua em formas de luta política, onde uns tendem a centrar sua preocupação nas pessoas e outros na natureza, embora estes últimos, muitas vezes, o façam sob perspectivas também antropocêntricas. Existe também, muitas vezes associado ao exemplo anterior, o estabelecimento de prioridades políticas onde o foco em certas pautas dificulta uma perspectiva mais abrangente. E existem, ainda, razões associadas às matrizes teórico-metodológicas que trazem embutidas, implicitamente, concepções normativo-prescritivas que delimitam o campo de reflexão, mesmo que esses limites não constituam posições deliberadamente assumidas pelo pesquisador.

Em termos gerais, e num esquema reducionista, o que se tem é que, em muitas abordagens preservacionistas ou conservacionistas, o paradigma informado pelas Ciências Biológicas tende a entender a dinâmica das relações sociais em termos de senso comum, o que, por vezes, resulta em posições politicamente conservadoras, no sentido de que tendem a legitimar iniquidades que são produto de relações sociais. Já no caso das perspectivas informadas pelas Ciências Humanas, são raras as vezes em que se investem esforços sistemáticos em revisar os pressupostos antropocêntricos das suas disciplinas. ${ }^{11}$

Como resultado, muitas das análises realizadas em nome da justiça ambiental, ao enfatizar as implicações ambientais dos conflitos e clivagens sociais, tendem a incorporar concepções normativas que carregam a noção de que o ser humano é o único sujeito realmente digno de consideração moral, sem fazer grandes esforços no sentido de identificar esta limitação e superá-la.

\footnotetext{
regra. É neste sentido que estes modos de vida possuem um conteúdo heurístico para a sociedade contemporânea, na medida em que mostram o problema e apresentam pistas tangíveis para a sua solução. Em outras palavras, são exemplos de experiências de vida onde a Ética e Justiça Ecológica é, se nem sempre existente, ao menos plausível.

${ }^{11}$ Discussões que envolvem antropólogos e outros atores vinculados à conservação e à luta pelos povos indígenas, sem dúvida, acrescentam uma grande variedade de nuances e até rupturas paradigmáticas com relação ao esquema enunciado. Talvez um dos maiores expoentes desse debate seja o perspectivismo de Eduardo Viveiros de Castro (2002). Um trabalho que relata a dificuldade em estabelecer categorias fixas neste espinhoso debate encontra-se em Gerhardt (2008).
} 
Esta situação reproduz uma divisão do trabalho acadêmico e político, onde os preocupados pelas questões relativas à face ambiental da injustiça social mantêm, em suas reflexões, as questões éticas relativas ao tratamento aos seres não humanos na sombra. Com isto, perde-se uma parte importante da potencialidade crítica da reflexão ambiental e perde-se a chance de pensar substantivamente como e em que medida ambas as questões estão inter-relacionadas.

Esta divisão não resolve os desafios ético-políticos deflagrados pelos processos de desenvolvimento contemporâneos. Isto porque, como mencionado acima, os processos sociais que resultaram nas desigualdades que o apelo à equidade tenta remediar estão eles próprios, muitas vezes, assentados numa específica valoração do ambiente e da natureza. É essa valoração que requer, ela própria, uma revisão, na medida em que se assenta num tratamento meramente instrumental dos animais e da natureza, considerando eles como mera coisa, imputação esta que não resiste ao exame crítico.

Por um lado, como sinaliza Acselrad (2008), os impactos ambientais "não são democráticos", no sentido de que não afetam a todos por igual, como tentam sugerir algumas retóricas que apelam à figura da "crise global". Também é defensável que os interesses de humanos, especialmente daqueles que estão em condições de maior vulnerabilidade, sejam estabelecidos como prioritários.

Mas, por outro lado, não são claras as justificativas éticas, nem também as analíticas, para simplesmente ignorar o leque de questões levantadas pela crítica ao antropocentrismo. Esta limitação leva a negligenciar as injustiças contra os seres vivos não humanos que as injustiças entre humanos tendem a produzir. Com efeito, é mais ou menos evidente que, numa sociedade em que o caráter instrumental tende a colonizar todas as relações entre os seres humanos, os seres vivos não humanos tenderão também a ser coisificados. No entanto, é muito menos evidente que, na medida em que aceitamos relações meramente instrumentais com os outros seres da natureza, inevitavelmente nos enredaremos em relações apenas instrumentais entre seres humanos.

O projeto ético-político de uma abordagem que concilie a inclusividade social com a inclusividade dos seres não humanos ainda está em aberto e a sua necessidade ainda não é suficientemente trabalhada, nem por analistas, nem por ativistas. Tal projeto implica em reconhecer que tanto o valor da equidade social quanto da expansão da consideração moral para além dos humanos são elementos necessários de perspectivas ambientais que superem as concepções de sustentabilidade falhas e restritas, por serem tecnocráticas e economicistas.

O desafio teórico-metodológico para avançar neste projeto é muito grande, podendo ter caminhos teóricos e referências empíricas diversas, e certamente excede às possibilidades de uma proposição individual.

O quadro traçado por Porto (2013) já aponta alguns âmbitos em que os conflitos ambientais ocorrem associados à valoração não meramente instrumental da natureza por parte de populações tradicionais. De um modo mais amplo, na América do Sul, observa-se um crescente debate envolvendo a perspectiva do Bem Viver inerente às culturas indígenas da América e às formas de desenvolvimento alternativas (Gudynas, 2011, dentre outros). Políticas públicas de desenvolvimento, associadas a concepções de felicidade amparadas em concepções de natureza com valor moral, como no caso do Butão, têm recolocado a centralidade das valorações subjetivas e culturalmente situadas como fator crucial das finalidades do desenvolvimento (Thinley, 1999). A exacerbação da concepção de seres sencientes não humanos como meras coisas, 
que sustenta a cadeia industrial de produção animal, tem levantado a crítica de defensores de animais e o questionamento ético dos padrões de desenvolvimento a ela associados (Nibert, 2013; Felipe, 2012; Florit \& Grava, 2013; Florit \& Sbardelati, 2016).

Em todos esses casos (cujo aprofundamento não cabe neste artigo), há pertinência em associar normativamente a problemática da consideração moral de seres não humanos - ou seja, a crítica ao antropocentrismo - com o imperativo da equidade social. No entanto, mesmo que essa perspectiva normativa seja viável e necessária, os processos sociais concretos não atendem espontaneamente a esse tipo de razões. Isto porque o problema de conciliar inclusão social com consideração moral de seres vivos não humanos não passa apenas por problemas de argumentação ética normativa, mas também pelas relações sociais e de poder concretas que se estabelecem em função de interesses e pelas moralidades naturalizadas reproduzidas socialmente.

É neste campo de disputa que a defesa das múltiplas valorações da natureza que encarnam os povos tradicionais deve ser considerada como prioritária. Eles defendem seus legítimos direitos a sustentar seus modos de vida, mas também têm uma contribuição de valor heurístico inestimável para os setores reflexivos da sociedade urbano-industrial.

\section{Considerações finais}

Atentar aos âmbitos em que acontecem os principais conflitos ambientais permite perceber com clareza que os mesmos, muitas vezes, envolvem populações cujo modo de vida está intimamente relacionado com as próprias valorações da natureza. Estas concepções, embora contenham uma valoração de uso da mesma, não implicam necessariamente numa redução da natureza a um estatuto meramente instrumental. Pelo contrário, trata-se de uma relação com a natureza carregada de sentidos e significações simbólicas - muitas vezes afetivas e que desafiam os esquemas ontológicos ocidentais - e de práticas de uso que denotam uma simultaneidade entre o uso dela e a sua consideração moral. Elas consistem em formas de valoração que muitas vezes são incomensuráveis com relação às realizadas pelos agentes do Estado e do mercado que executam os grandes projetos de desenvolvimento.

Trata-se de uma pluralidade de valores que se expressa na diversidade de modos de vida nos quais a natureza e a paisagem constituem valores de uso não redutíveis à mera monetarização em função de que detêm uma condição dual de significação simbólica e provimento material.

As análises da ética ambiental, que reconhecem algum tipo de valor intrínseco em seres vivos não humanos ou em unidades de paisagem, em geral, conflitam com a racionalidade exclusivamente instrumental que, ao se direcionar na consecução de fins econômico-monetários do Estado ou de certos atores sociais, não consegue reconhecer nesses seres ou paisagens outra característica que não a de mera coisa.

Por outro lado, as análises da ética ambiental que reconhecem valor intrínseco a seres vivos não humanos não necessariamente conflitam com racionalidades econômicas vinculadas a modos de vida cuja integração ao mercado não é completa e, portanto, não é completa a sua monetarização. Pelo contrário, esses modos de vida possuem espaços de integração e síntese entre sua racionalidade econômica e uma racionalidade de valores intrínsecos da natureza, na medida em que os valores reconhecidos não são monetários. A necessidade de subsistir materialmente invoca um valor econômico e moral, 
decorrente do direito à manutenção da própria vida reconhecido também aos outros seres.

A identificação de valorações não instrumentais é potencialmente importante na estratégia argumentativa de defesa dos direitos territoriais das comunidades tradicionais ameaçadas por projetos e obras de infraestrutura e para a fundamentação de uma Ética e Justiça Ecológica capaz de conciliar equidade social com consideração moral dos seres vivos não humanos.

Reconhecer esta potencialidade não implica absolutamente em imaginar ou pregar uma volta a um passado edênico ou mítico, de suposta harmonia perfeita entre seres humanos e natureza. Antes,

\section{Referências}

Acselrad, H. O que é justiça ambiental. Rio de Janeiro: Garamond Universitária. 2008.

Acselrad, H. Ambientalização das lutas sociais o caso do movimento por justiça ambiental. Estudos Avançados, 24(68), 2010.

Bourdieu, P. Cosas dichas. Barcelona: Gedisa, 1993.

Callicott, J. B. The Land Ethic. In: Jamieson, D. A companion to environmental philosophy. Malden: Blackwell Publishers, 2001. p. 204-217.

Claro, R. El desarrollo. Entre el simple crecimiento y el "Buen Vivir." In: Editorial: LOM, 1. ed., 2011. 388 p.

Crespo, S. Educar para a sustentabilidade: a educação ambiental no programa da agenda 21. In: Noal, F. O.; Reigota, M.; Barcelos, V. H. L. (Orgs.). Tendências da educação ambiental brasileira. Santa Cruz do Sul: EDUNISC, 2000.

Danowski, D.; Viveiros de Castro, E. Há um mundo por vir? Ensaio sobre os medos e os fins. Desterro, Cultura e Barbárie e Instituto Socioambiental, 2014.

Elliot, R. La ética ambiental. In: Singer, P. (Ed.). Compêndio de ética. Madrid: Alianza Editorial, 2004. p. 391-404. trata-se de explorar caminhos de superação de perspectivas dicotômicas que colocam em posições opostas o imperativo da equanimidade social e a consideração moral dos seres vivos não humanos.

\section{Agradecimentos}

Agradecemos aos/as avaliadores/as anônimos/ as, que contribuíram de maneira inestimável a melhorar o artigo e para a continuidade da reflexão aqui apresentada. Agradecemos o trabalho de revisão gramatical de Maria Roseli Rossi Ávila e de revisão de inglês de Marina Beatriz Borgmann da Cunha, do FURB Idiomas.

Felipe, S. T. Galactolatria. mau deleite: implicações éticas, ambientais e nutricionais do consumo de leite bovino. São José: Ed. da Autora, 2012. 303 p.

Florit, L. F.; Grava, D. S. Ética ambiental, especismo e desenvolvimento territorial sustentável. In: Anais do XXIX Congresso ALAS, Crisis y Emergencia Sociales en América Latina, Santiago do Chile, 2013.

Florit, L. F.; Grava, D. S. Equidade social e expansão da consideração moral para além dos humanos: uma conciliação fundamental para pensar a dimensão ambiental do desenvolvimento regional. In: Anais do $2{ }^{\circ}$ SEDRES-Seminário de Desenvolvimento Regional, Estado e Sociedade. GT 2 - Dados eletrônicos, 2014. Campina Grande, Paraíba: EDUEPB/UEPB. Disponível em: < http://sites.uepb.edu.br/ sedres/files/2014/04/GT2-ANAIS-completo.pdf $>$. Acesso em 08 mar. 2016.

Florit, L.; Sbardelati, C. Intensive Speciesism Regions in Brazil. In: Talia R.; Dora M. (Org.). Impact of Meat Consumption on Health and Environmental Sustainability. 1. ed. IGI Global, 2016. p. 277-294. 
Funtowicz, S.; Ravetz, J. The Worth of a Songbird: Ecological Economics as a Post-Normal Science. Ecological Economics, 10(3), 189-196, 1994.

Gerhardt, C. H. Pesquisadores, populações locais e áreas protegidas: entre a instabilidade dos lados e a multiplicidade estrutural das posições. Orientador: Roberto José Moreira. Rio de Janeiro, Tese (Doutorado em Ciências Sociais) - Universidade Federal Rural do Rio de Janeiro, UFRRJ, Brasil, 2008.

Giddens, A. A constituição da sociedade. São Paulo: Martins Fontes, 1989.

Gudynas, E. Ecología, economía y ética del desarrollo sostenible. 5. ed. rev. Coscoroba Ediciones, 2004.

Gudynas, E. Buen vivir: germinando alternativas al desarrollo. América Latina em Movimento - ALAI, 462, 1-20, 2011.

Hargrove, E. Weak Anthropocentric and Intrinsic Value. In: Ligth, A.; Rolston, H. Environmental Ethics: an anthology. Austrália: Blackwell Publishing, 2009.

Legarda, A. A.; Pardo, B. M. Justicia Ambiental. El estado de la cuestión. Revista Internacional de Sociologia (RIS), 69(3), 627-648, 2011.

Leis, H. A modernidade insustentável. As críticas do ambientalismo à sociedade contemporânea. São Paulo: ANNPAS, Annablume, 2014.

Martinez-Alier, J. O ecologismo dos pobres. São Paulo: Contexto, 2007.

Nibert, D. Animal Oppression \& Human Violonce. Domesecration, Capitalism and Global Conflict. New York: Columbia University Press, 2013.

Norton, B. Environmental Ethics and Weak Anthropocentrism. In: Ligth, A.; Rolston, H. Environmental Ethics: an anthology. Austrália: Blackwell Publishing, 2009.

Porto, M. F. S. Ecologia, economia e política: contradições, conflitos e alternativas do des-envolvimento. In: Rainer, R.; Hermes M. T. (Org.). Política e planejamento regional: uma coletânea. v. 1, 1. ed. Brasília: UP Gráfica, 2013. p. 61-75.

Rachels, J.; Rachels, S. Os elementos da filosofia da moral. 7. ed. Porto Alegre: AMGH, 2013. 208 p.
Regan, T. Jaulas vazias: encarando o desafio dos direitos animais. Porto Alegre: Lugano, 2006. 294 p.

Sack, R. D. O significado de territorialidade. In: Dias, L. C.; Ferrari, M. Territorialidades humanas e redes sociais. Florianópolis: Insular, 2011. 261 p., il.

Singer, P. [1994]. Ética prática. São Paulo: Martins Fontes, 2002.

Singer, P. Libertação animal. Tradução de: Animal Liberation. v. XXIV. Ed. rev. Porto Alegre: Lugano, 2004. 357 p., il.

Taylor, P. W. [1986]. Respect to Nature: A Theory of Environmental Ethics. Princeton University Press, 2011.

Theis, I. M. (Org.). Desenvolvimento e território: questões teóricas, evidências empíricas. Santa Cruz: EDUNISC, 2008.

Thinley, L. Y. Values and Development: "Gross National Happiness". In: Gross National Happiness: a Set of Discussion Papers, chapter 2. Journal of Bhutan Studies. 1999. <http://www.bhutanstudies.org.bt/gross-nationalhappiness-a-set-of-discussion-papers/>. Acesso em: 09 mar. 2016.

Thomas, K. O homem e o mundo natural: mudanças de atitude em relação às plantas e aos animais (1500-1800). São Paulo: Companhia das Letras, 1988. 454 p., il.

Varner, G. Sentientism. In: Jamieson, D. A companion to environmental philosophy. Malden: Blackwell Publishers, 2001. p. 192-203.

Viveiros de Castro, E. B. A inconstância da alma selvagem e outros ensaios de Antropologia. São Paulo: Cosac \& Naify, 2002. 552 p.

Viveiros de Castro, E.; Danowski, D. Diálogos sobre o fim do mundo. Entrevista concedida a Eliane Brum. Diário El País, Edição Brasil, 24 de setembro de 2014. Disponível em: <http://brasil.elpais.com/brasil/2014/09/29/opinion/1412000283_365191.html>.Acesso em: 08 mar. 2016.

Zhouri, A.; Oliveira, R. Quando o lugar resiste ao espaço: colonialidade, modernidade e processos de territorialização. In: Zhouri, A.; Laschefski, K. (Org.). Desenvolvimento e conflitos ambientais. Belo Horizonte: Editora UFMG, 2010. 